\title{
Investigation of vibration assisted drilling prospects for improving machining characteristics of hard to machine materials at high and low frequency ranges
}

\author{
V. Ostaševičius*, G. Balevičius**, R. Zakrasas***, J. Baskutienė****, V. Jurẻnas****** \\ *Kaunas University of Technology, Studentu str. 56, Kaunas, Lithuania, E-mail: vytautas.ostasevicius@ktu.lt \\ **Kaunas University of Technology, Studentu str. 56, Kaunas, Lithuania, E-mail: gytautas.balevicius@ktu.edu \\ ***Kaunas University of Technology, Studentu str. 56, Kaunas, Lithuania, E-mail: robertas.zakrasas@outlook.com \\ ****Kaunas University of Technology, Studentu str. 56, Kaunas, Lithuania, E-mail: jbask@ktu.lt \\ *****Kaunas University of Technology, Studentu str. 56, Kaunas, Lithuania E-mail: vytautas.jurenas@ktu.lt \\ cross $^{\text {ref }}$ http://dx.doi.org/10.5755/j01.mech.22.2.14431
}

\section{Introduction}

Constantly increasing industrial demands and technological advances in material science provide incentive for adoption of new materials and machining methods, in order to gain competitive advantage and overall improvement of new and existing applications. Adoption of new materials or practices generally raises challenges to the overall machining processes employed in the production process. Usually the desired property or outcome of newly adopted material or practice comes at the expense of machining capabilities of already employed machining methods. Often the material in question does not behave in a conventional way when machined via conventional methods; therefore, machining parameter restrictions need to be imposed on the machining method to prevent the variability of material response to the machining process. Not adhering to these restrictions is almost always sure to result in tool breakage, poor final product quality etc.

The methods, to improving the machinability of a material, can be distinguished into two categories: introduction of a completely new machining method, or improvement of the existing method. The first approach usually requires fundamental innovation to occur - a new machining method to be invented, this approach however, carries with it high costs and risks, as new machining methods are usually costly and poorly understood, when in the initial stages of development. The second approach is more adaptable and less costly, as usually, existing machinery can be employed.

A promising branch of existing machining method improvement approaches is a group of methods employing auxiliary processes to aid the conventional machining processes. In the last few years there has been a growing interest of employing these methods, commonly referred to as hybrid machining methods [1], where auxiliary processes among many, include chemical erosion, electrical discharge etc. These added processes enable effective material removal and address some common issues encountered in conventional machining processes [2]. A relatively flexible and inexpensive group of hybrid machining methods is referred to as vibration assisted machining methods (VAM). Here methods can either employ direct vibrational excitation, which relies on adjusting the trajectory of the tool, inverse excitation, which vibrates the workpiece rather than the tool, or a combination of both [3].
The challenges to the machining capability arise either from the change of the material itself, or introduction of machining practices incompatible with the material properties in question. It can be observed when adopting hard-brittle materials to technological processes. These materials are extensively in use where properties, such as high thermal stability, dielectric strength, low thermal conductivity, thermal shock resistance and low abrasive wear are necessary, the use of such materials range from applications of alumina (A12O3) substrates for thin film electronic circuits, load bearing hip prostheses, dental implants [4], zirconia ceramics in bearings, $\mathrm{pH}$ meters, fuel cells, infrared radiators, thread guides, pressure sensors, oxygen sensors and total hip replacement ball heads [5], various glasses in communications, medical equipment, nuclear waste storage [6], high precision optical instruments etc. Machining of such materials, especially in high precision requiring cases (optical elements, mold inserts, substrates etc.) requires high quality surface finish which require machining in ductile regime. Extensive studies have been conducted into requirements for ductile regime machining in the past, proposing different models of ductile deformation [7], however in most cases the common conclusion reached, was that reduction of the machining scale to a sufficient point will result in ductile deformation. However, ductile regime machining of hard-brittle materials using conventional methods is not cost effective. In presence of increased number of required tool passes to achieve required geometry, high machining temperatures that have negative impact not only on the parameters of machined material (dimensional deviation), lifetime of the cutting tool, but also on the dimensional accuracy of finished part are observed [8].

Improvement of existing machining method to enhance current machinability of certain materials can also be noted in the case of skeletal trauma-correction procedures which usually involve drilling of the osseous tissue, for internal and external fixation. These procedures involve, but are not limited to, surgical operations that encompass applications of various orthopaedic and orthodontic implants, stabilization of limb bones with the help of external fixation apparatuses, common dental care procedures. Even correctly applying current machining methods, in this case drilling, may not always yield desirable results, since bone is a brittle non-homogenous composite material with hard compact bone on the outside and soft porous bone on the inside, and because bone properties have great variability 
that are dependent on bone type, patient's skeletal health, any negative condition associated with patient's locomotion or physical condition.

With the outline of the literature overview, provided in the previous paragraphs it becomes apparent, that machining problems discussed, regardless of the nature of their machining parameter limitation, both have some type of restrictions imposed on them. Since drilling is a common machining operation for both instances of the machining problems and is especially common in bone drilling case, this article will attempt to employ variations of the VAM method as solutions to the above described problems, in a parallel manner, in order to observe the applicability of the method at different frequency ranges. The resulting findings will serve as a motivation and a guideline for further indepth research of applications to each problem. The aim is to be achieved by completing these objectives:

1. Propose an experimental methodology to observe the effect of vibrational excitation on drilling of hard-brittle materials;

2. Propose an experimental methodology to observe the effect of vibrational excitation on drilling of bone tissue;

3. Conduct experiments;

4. Investigate and discuss the results.

\section{Experimental procedures}

As has been established in the previous chapter, VAM methods, relies on the application of auxiliary vibrations to the tool or the workpiece, and depending on vibration frequency different vibration modes can be observed longitudinal, transversal and torsional. The crucial difference, when comparing vibration assisted drilling (VAD) to conventional drilling (CD), the work-piece and the tool are in continuous contact with each other when considering the conventional drilling scenario, whereas in VAD the contact is intermittent as the trajectory of the tool is affected by minute amplitudes, in directions dependent on the vibration mode. The intermittent contact has been reported to provide benefits in the form of reduced tool wear, cutting forces [9] VAM methods are generally distinguished into low and high frequency applications, those in the low frequency category are several orders of magnitude below the ultrasound threshold, while high frequency applications tend to exceed it. Both categories have found their applications in industry and will be considered, when proposing the experimental methodology for each problem.

VAM systems can either be designed to be operated at discrete frequencies (resonant system) or on a frequency range (non-resonant system) [10]. VAM is increasingly gaining popularity as more rational choice over conventional machining of hard to machine yet desirable materials, as is evident from the multitude of existing and ongoing research in the area. Generally, the investigations can be ranged by different choices of the main process, vibration parameters, and material. A commonly investigated group of methods belong to cutting of metals and other materials. For instance, quite recently, Zhang et. al. [11] investigated the effect of linear versus elliptical vibration in microgrooving of $0 \mathrm{Cr} 18 \mathrm{Ni} 9$ work-piece, and found that in the linear vibration case, the surface roughness is lower, while in the elliptical case the lower cutting forces were observed. Additionally, Skiedraite et. al. [12] performed acoustic emission measurements during metal cutting with ultrasonic vibrational excitation and without it. The research employed a special cutting tool excited by piezo ceramic actuators, at frequencies in the range of $30 \mathrm{kHz}$. The results of the research have shown significant stabilization of acoustic emissions and increase in surface quality in the case of tool excitation. Nath et. al [9] have found the cutting tool life to be extended up to 4-8 times when machining Inconel 718, in comparison to conventional cutting case. Research into methods employing rotating tools has been active over the period as well. For instance, Ostasevicius et. al. [13] developed and experimentally verified finite element model of vibration milling tool, that was treated as a pre-twisted cantilever in the modelling process. When compared to conventional milling, vibrational milling has shown significant decrease in surface roughness in milling of stainless steel and titanium workpieces. As a result of these findings, researchers have proposed application of the method for improved machining of brittle materials

Since the main process of the hybrid machining method in VAM category, for both problems is the same drilling, we will now consider the application of the high frequency application of VAD process - ultrasonically assisted drilling (UAD). UAD operates at oscillations at excitation frequencies of the order of magnitude of $20 \mathrm{kHz}$ and higher, and is one of the more prevalent applications of VAM. UAD has been mostly applied to drilling of metals and other hard-brittle materials. Applications of UAD to human bone drilling are limited, due to the temperature limitation, since as shown by [14] the tool tip temperature increases when compared to the conventional drilling case. In light of presented conditions of UAD it is apparent, that it is more suited to machining of hard-brittle materials and therefore will be considered for experimental procedure of that particular problem. In presence of limitations imposed on UAD by specific bone machining tissue conditions, the natural course of action is to investigate the complete opposite possibility of UAD - low frequency vibration assisted machining. If limitations of the latter method do not exceed $\mathrm{UAD}$, it will be considered for experimental procedure development for investigating the bone tissue drilling case.

Low frequency vibration assisted (LFVAD) drilling is a hybrid machining method where auxiliary low frequency oscillations are superimposed to the drilling tool, just like is the case with UAD, external excitations may be applied either to the tool, to the workpiece or both. The frequency of LFVAD processes typically does not reach $1 \mathrm{kHz}$, this motion then, may be achieved using simple linear actuators, cam systems added to the drilling or cutting machine, utilizing other controllable vibration inducing equipment. This non-continuous cutting action has the benefit of producing thinner chips which break more easily, has a positive effect of better material removal. A study by H.G. Toewes et al. [15] was done to see the influence superimposed lowfrequency modulation had on the drilling process of aluminum 6061. This ductile material was chosen, because it was easy to compare obtained chips with CD results. The samples ware vibrated at frequencies of $25 \mathrm{~Hz}-75 \mathrm{~Hz}$ using piezoelectric stacked translator and drilled using a simple HSS drill bit. The results indicated reduced thrust force, as well as marked reduction of chip length when compared to conventionally drilled samples. The effects associated with positive results were observed when imposed vibration frequency $f_{p}$ relationship with drill bit rotational frequency $f_{d}$ 
ratio $\left(f_{p} / f_{d}\right)$ was an odd integer. Applying LFVAD as a machining process to non-ductile, composite materials has also shown some merits. A. Sadek et al. [16] studied characteristics and possible optimisations of LFVAD of fibre epoxy laminates and demonstrated that by utilizing low frequency modulation $(30 \mathrm{HZ}$ and $60 \mathrm{~Hz}$ ), which was generated using electromechanical shaker, and high amplitude with increased feed rate or higher rotational speed it is possible to observe lower axial forces and temperatures compared to CD. It was also demonstrated that application of external excitations improved obtained hole surface finish when compared the surface roughness value $\mathrm{Ra}$ to value obtained in CD. The reduction of drilling forces can be constituted to intermittent cutting, which helped in producing thinner chips. By utilizing LFVAD in hard to machine composite stack material machining, it is possible to obtain lower cutting process temperatures, thus making it possible to extend tool life, obtain better surface finish. A study by Oliver Pecat et al. [17] compared the influence LFVAD has on the tool wear when drilling compound materials of carbon fibre reinforced plastic and titanium alloy (CFRP/Ti6Al4V), these results then were contrasted with $\mathrm{CD}$, and it was recognized that in addition to reduction of drilling temperature, the tool wear was significantly lower. The reduction of chip length, constituting from application of LFVAD, also had a positive effect in material removal.

Three main tasks when defining the experimental procedure in the case of UAD application to hard-brittle materials are the selection of the tool and selection of the workpiece material and the selection of important metrics to be analysed. As is apparent in the previously discussed studies of VAM application - commonly encountered hard-brittle material UAM studies focus on, measuring surface quality, machining forces, temperatures etc. Machining forces, in this case, the axial drilling force and expected reductions are readily available when conducting dynamometer force plate measurements during the drilling process. Reductions in machining forces have been demonstrated to point towards improved machinability, as shown by [18]. Hence reductions of the axial force will be considered to have a positive effect on the process. Additional measure of the effect is preservation of sample integrity throughout the machining process. Considering currently available information - the main objective of the first experiment is to determine the change of the axial drilling force, when subjecting hard-brittle materials to ultrasonic excitation. The next task is to choose a material to be subjected to UAD in order to illustrate the effect. Glass is one of the more difficult to machine hard-brittle materials, as it possesses high hardness but low fracture toughness. Therefore, in this machining experiment, glass is chosen as a representation of the hard-brittle material raster, if positive effects are observed, in future experiments, materials with more specific applications will be chosen. A series of $1 \mathrm{~mm}$ glass plates were chosen as the workpieces, in order to increase the machining difficulty, as at lower thickness, preservation of the sample integrity becomes a challenge. The machining is conducted with and without ultrasonic excitation. Two types of tools were chosen, by observing the industrial processes applied to glass machining. In industry glass drilling is more akin to grinding as tools tend to employ abrasive particles. The first type of tool is meant to represent the best case scenario - a crown drill specifically used in glass drilling applications. The second tool is a ball end abrasive mill and is meant to represent scenario in which a more universal tool bit is forced to perform on par with the tool intended for the specific job.

To perform the drilling experiments "Leadwell" V20 CNC milling machine (Fig. 1) was employed. Thin microscope slides were used as drilling samples, while both types of tools were fixed into an ultrasonic tool holder. The operational frequencies were observed by determining the frequencies producing the highest amplitudes. However, no further attempts into determining the vibration modes were made.

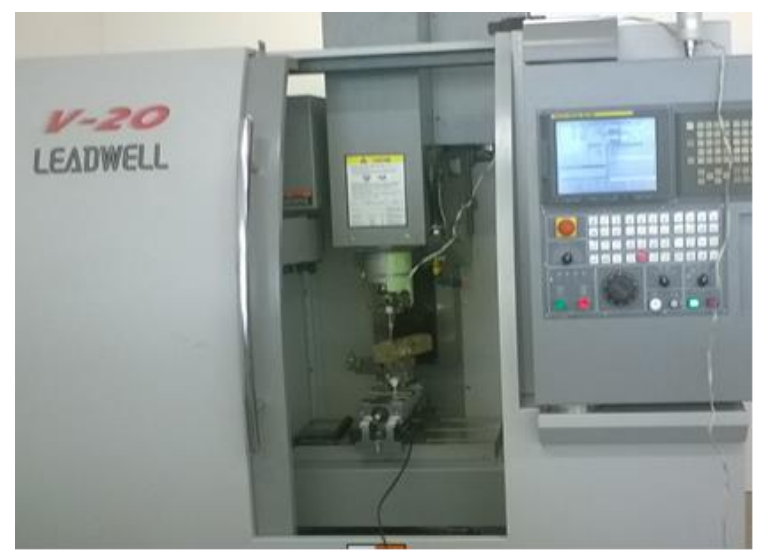

Fig. 1 "Leadwell" V20 CNC milling machine

As it has been established, two types of tool were used for the experiment; the dimensions of choice were $\emptyset 25 \mathrm{~mm}$ and $\emptyset 5 \mathrm{~mm}$ for crown drill and spherical abrasive mill respectively. In the case of each tool, a drilling attempt was made under conventional conditions and in presence of vibrational excitation. When subjected to ultrasonic excitation, manual frequency scanning showed the crown drill and spherical abrasive mill to respond strongest at frequencies of $15.9 \mathrm{kHz}$ and $21 \mathrm{kHz}$ respectively. Considering the difference between the tools, amplitudes of the vibration were disregarded in this case and frequencies of $15.9 \mathrm{kHz}$ and $21 \mathrm{kHz}$ were chosen as the operational parameters for the crown drill and spherical abrasive mill respectively.

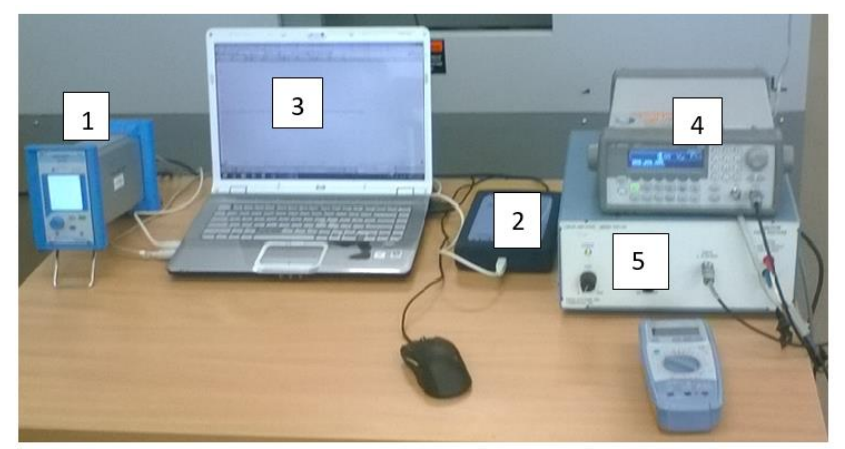

Fig. 2 Experimental setup: 1 - charge amplifier Kistler 5018A; 2 - oscilloscope Picosope 3424; 3-PC; 4 - signal generator Agilent 33220A; 5 - amplifier EPA-104

Outlined in the following paragraph is the experimental setup employed when investigating the effect of UAD application on hard-brittle materials, for measurement of the axial forces and producing the driving signal for the ultrasonic transducer. The axial forces were measured by employing a force-torque sensor Kistler 9365B. The signal 
from the sensor is amplified by Kistler 5018A charge amplifier (Fig. 2, (1)), and subsequently passed to Picoscope 3424 oscilloscope (Fig. 2, (2)) and subsequently represented by the PC (Fig. 2, (3)). The signal for the tool transducer is generated by the signal generator Agilent 33220A (Fig. 2, (4)) and amplified by the signal amplifier EPA-104 (Fig. 2, (5)) before being passed to the transducer, the wide range signal generator allows achieving the desired frequency of the signal, while the amplifier allows adjusting the amplitude to a higher scale.

The experimental procedure itself followed two termination conditions. Drilling was conducted until the fracture occurred or the plate was drilled through. In order to avoid premature fracture of the samples the drilling parameters were limited to $2000 \mathrm{rpm}$ and feed rate of $0.2 \mathrm{~mm} / \mathrm{min}$ as per industry observations. During the machining process the samples were affixed to a wooden base by a cyanoacrylate glue and were later removed using immersion in an acetone solution.

As was in the previous case, the defining task of the entire experimental setup is the definition of the metric being observed. The topic of interest to the researchers and medical personnel in the field, is that of the drilling temperature of the bone. It has been shown that elevated temperatures at the bone drill interface may lead to irreversible changes in the bone tissue, a condition called necrosis of the bone, which may be responsible for further complications such as, implant failure and longer healing times [19]. The improvements suggested by the scientific community to the method of machining the bone, namely drilling, incorporate the use of external and internal irrigation systems at the drill site [20], careful control and selection of favourable cutting parameters [21], application of automatic or mechatronic systems [22]. Predicament occurs when the need for uniform and consisted samples in the experimental investigation are required considering bone is a non-homogenous material with different properties depending on its type and which particular bone it is. In order to imitate human bone in experimental setups, animal bones (bovine, ovine, porcine), or polymers having similar mechanical properties are generally used. Polymers have the advantage of being homogeneous, easy to shape and form depending on the requirements of the particular experimental setup, as well as allowing to achieve greater repeatability compared that to animal bone.

Therefore, the main objective of this experiment was to determine the drilling temperature using LFVAD in comparison to conventional drilling. Additionally, bone tissue was substituted by a $4 \mathrm{~mm}$ thick PMMA sample in order to ensure replicability, as bone properties differ over the investigated domain. The successful effect of the application is judged by how low the measured temperature is when compared to conventional drilling, and the critical temperature value.

Since most bone drilling operations in medical environment are performed by hand, all drilling runs were carried out using Makita 8391DWPE hand drill with $4.2 \mathrm{~mm}$ diameter two flute HSS drill bit. The drill was set to $1200 \mathrm{rev} / \mathrm{s}$ drilling speed. In order to determine the drilling temperature thermal camera FLIR T450sce was used. Considering the drilling was done by hand, in addition to temperature, forces were measured and monitored during the drilling process as well, using force/torque gauge model
BGI-Mark-10, this was done however only to ensure a decent level of replicability, and avoid biases resulting from possible operator error, rather than to draw conclusions related to drilling force changes. The block diagram of the used equipment and their relationship between each other can be seen below (Fig. 3).

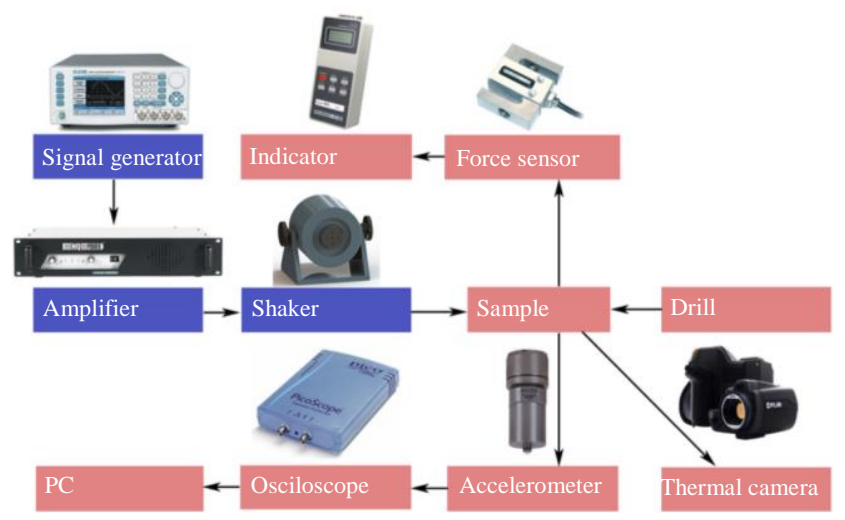

Fig. 3 Block diagram of low frequency vibration assisted experiment

The low frequency electromagnetic vibrator driving setup was used as follows: sine wave oscillations were generated by signal generator WW5064, they were then amplified with VPA2100MN amplifier to drive electromagnetic vibrator VEB ROBTRON MESS-ELEKTRONIK OTTO SHON. Additionally, to obtain consistent vibration amplitudes between samples Schwingungsaufnehmer KD35 accelerometer was utilized in conjunction with PicoScope 4226 digital oscilloscope.

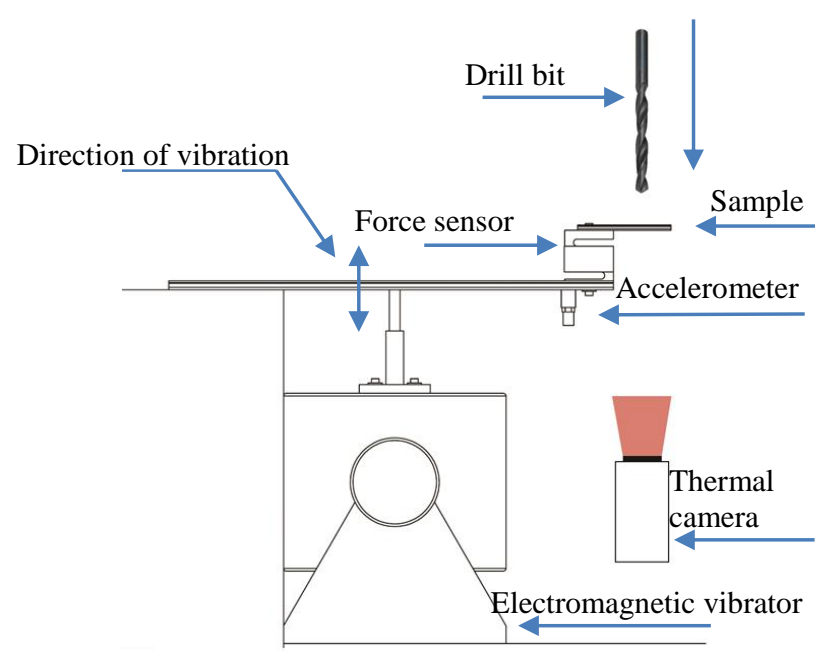

Fig. 4 Scheme of the experiment

As with the previous experimental setup, the termination conditions remained the same, however, the dependence of vibration frequency on the temperature was of interest. Fig. 4 presents a graphical representation of the experimental setup for measuring the temperature during LFVAD of PMMA plate. Sample was subjected to excitation and drilled using the hand drill, while maintaining the thrust force at the steady level of $30 \mathrm{~N}$, at the same time the thermal camera was used to obtain temperature measurements; the filming was conducted from below the sample (Fig. 5, (1)), at the predicted position of the exit hole which could be visually determined (Fig. 5, (2)), taking into account the small thickness and favorable optical properties of PMMA. 
In order to protect the camera lens from falling chips, it was positioned one meter away and at an angle as shown in Fig. 5. At the moment when the drill went through the material, the observed temperature was considered to be the maximum drilling temperature, as at that point all of the frictional energy of the drilling process was expected to be converted to heat.

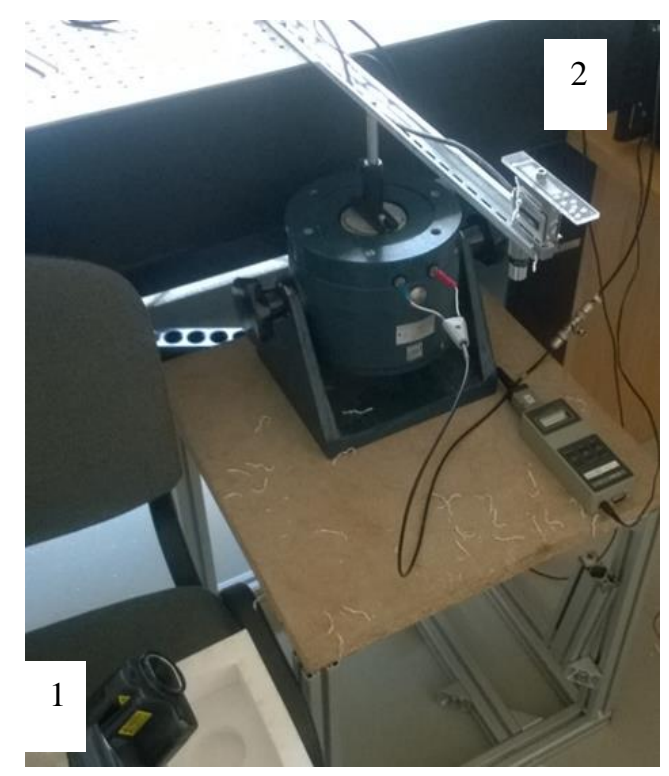

Fig. 5 Experimental setup: 1 - thermal camera position; 2 - sample position

\section{Results and discussion}

The first experiment provided response in the form of axial force measurements. In total four experimental runs were conducted, as in this case resonating modes of the tool were employed. Provided below are smoothed graphs of axial forces. The trends are compared as - excited V.S. conventional cases for both tools (Fig. 6, Fig. 7).

The drilling using spherical mill in the conventional drilling was terminated prematurely, due to a fracture of the sample (Fig. 8, (1)). Under excitation both tools operated without a fracture (Figs. 8-9, (2)), however, considering the fact that spherical abrasive ball end mill was considered to represent the harder case scenario, UAD of glass plates can be considered to have by default demonstrated superiority over the conventional case.

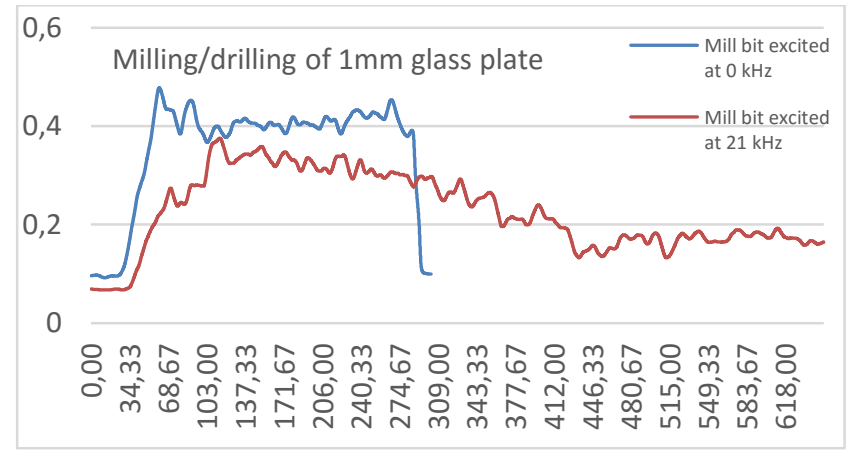

Fig. 6 Axial force results for drilling with spherical mill (excited vs. conventional)

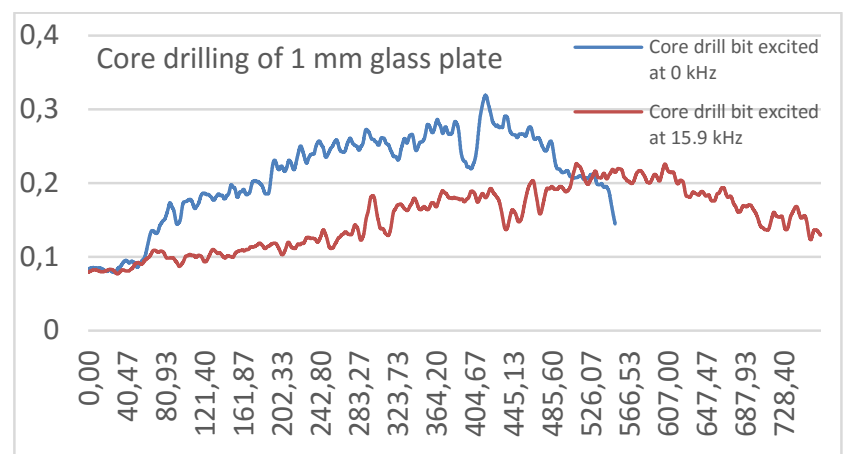

Fig. 7 Axial force results for drilling with core drill (excited vs. conventional)

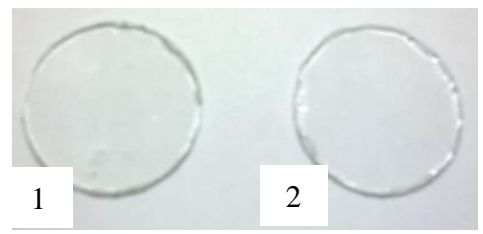

Fig. 8 Core drill samples: 1 - conventional case; 2 - under excitation

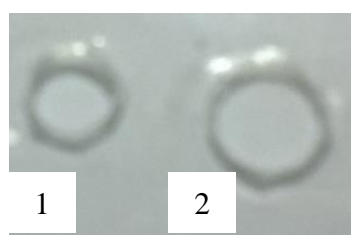

Fig. 9 Spherical mill drilling samples: 1 - conventional case, 2 - under excitation

Core drilling under conventional conditions, however went through with minimal fracture as well, yet this was to be expected, as the tool was specifically designed to handle such materials, however, due to a mismatch between the available sample size and the size of the core drill, the integrity of the samples could not be preserved (Fig. 7).

Summing up the results of the first experimental run, UAD has demonstrated superiority over its conventional counterpart in terms of axial drilling force reduction and sample integrity preservation. It is apparent that in both cases, the peak axial force was lower for the case of the excited tool. Additionally, the drop of the axial force was less abrupt in the excited tool case, due to preservation of sample integrity throughout the drilling process (demonstrated by the length of the graph). Further investigations should focus on more specific applications of glass or other hard-brittle materials, however, considering the obtained results, UAD should be considered as the method of choice for use in upcoming machining studies of these hard to machine materials.

The response for the second experiment, the bone tissue drilling case, in which PMMA was used as a substitute to ensure consistency of the results, was obtained in the form of temperature measurements at the very end of the drilling run. In grand total the investigation was conducted at 9 different vibration settings, performing 10 drilling runs for each vibration setting. Vibration frequencies for the drilling were selected every $20 \mathrm{~Hz}$ from $60 \mathrm{~Hz}$ to $120 \mathrm{~Hz}$ disregarding the excitation mode or amplitude (Fig. 10). 


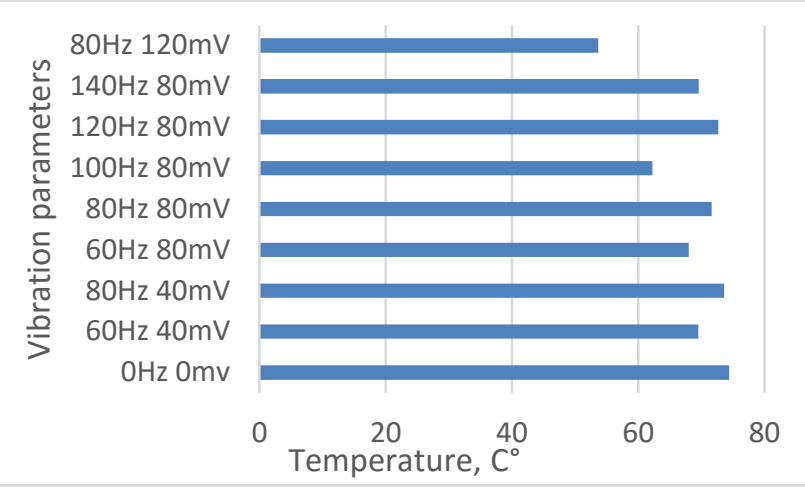

Fig. 10 PMMA drilling temperature dependency on vibration assisted drilling parameters

After reviewing recorded data, it was deemed important to ignore highest obtained temperature if at the time the temperature reading indicated the chip (Fig. 11, (2)). Only the surface of the drill hole (Fig. 11, (1)), was taken into account as an applicable temperature measurement location.

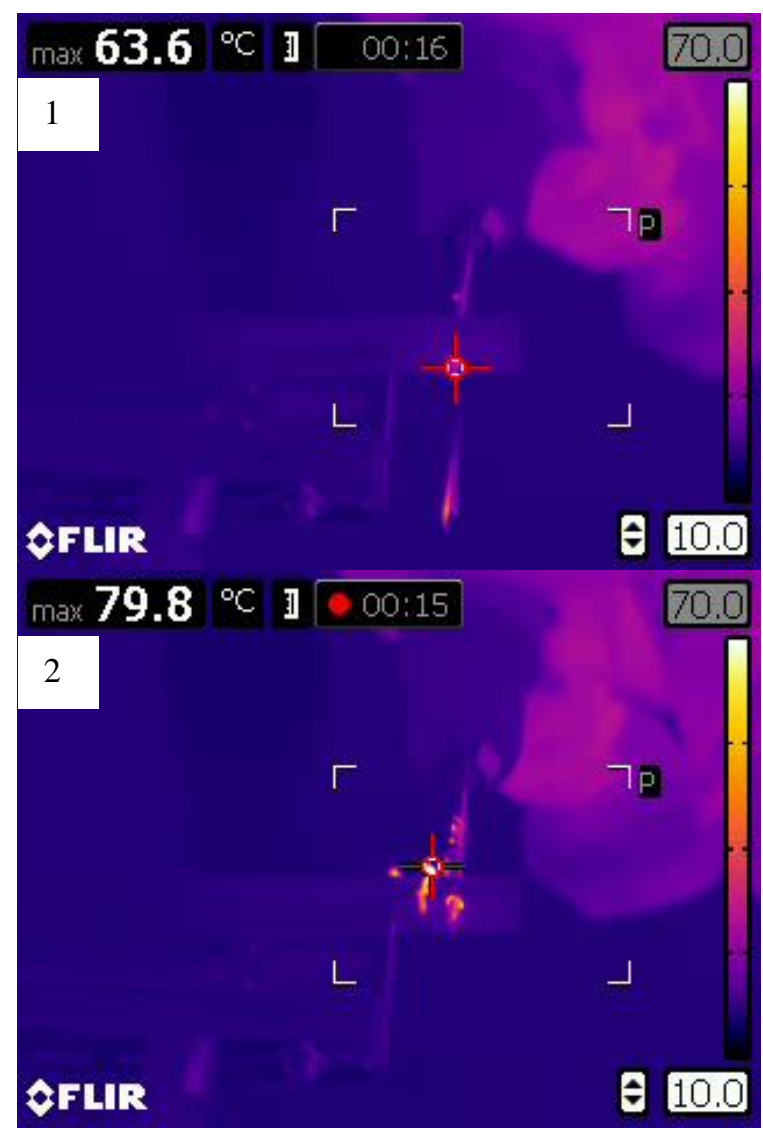

Fig. 11 Highest observed temperature: 1 - hole; 2 - chip

Further examining Fig. 10 it is obvious that some parameters of vibration assisted drilling had little to no effect on the obtained temperature at the exit hole. Out of all of the added vibration parameter combinations, the entries that show the least positive effect are $60 \mathrm{~Hz} 40 \mathrm{mV}$ and $80 \mathrm{~Hz} 40 \mathrm{mv}$ (these modes show increase in drilling time as well), in essence one could argue that the amplitude at which these samples were oscillated was not suited to produce positive results. Samples which had their amplitude signal set at $80 \mathrm{mV}$, more or less showed positive results in comparison. In particular, samples with frequency of $60 \mathrm{~Hz}$ and
$100 \mathrm{~Hz}$ show sizeable decrease in temperature of $6^{\circ} \mathrm{C}$ degrees and $11^{\circ} \mathrm{C}$ degrees respectively. Vibration parameters of $80 \mathrm{~Hz} 120 \mathrm{mV}$ showed the greatest decrease, as it not only drastically reduced drilling temperature by $21^{\circ} \mathrm{C}$, but also had a 1.4 second faster drilling time. Vibration frequencies that show biggest reduction of temperature $(80 \mathrm{~Hz}$ $120 \mathrm{mV}, 100 \mathrm{~Hz} 80 \mathrm{mV}$ and $60 \mathrm{~Hz} 80 \mathrm{mV}$ ).

From obtained results it is apparent that some vibration frequencies and amplitudes are better suited in lowering drilling temperatures than others. It is also worth noting that some vibration settings produce worse or similar results compared with conventional drilling. Further studies in this topic should investigate in greater depth; the influence the vibration amplitude and excitation mode have on the drilling temperature and time.

\section{Conclusions}

Literature overview of hard to machine materials was done. In addition, hybrid machining methods as a solution for better machinability were examined. Two experiments were proposed and conducted, utilising two different VAD techniques in drilling of hard to machine materials. Both experiments focused on different metrics, in accordance to their specific applications. In the first experiment UAD was employed in drilling thin glass plates to determine axial forces when compared to $\mathrm{CD}$. In the second experiment LFVAD was used to drill PMMA samples to determine the difference in drilling temperature when compared to $\mathrm{CD}$.

UAD experiment demonstrated reduction of drilling force as well as its ability to preserve sample integrity. The change of axial force when drilling with external excitations was reduced, compared to CD sample.

LFVAD experiment displayed the reduction of drilling temperature of up to $21^{\circ} \mathrm{C}$ in some oscillated samples. The use of thermo-graphic imaging showed that it is a viable drilling temperature examination tool. Further investigation should be done on the influence of vibration amplitudes and excitation parameters.

\section{References}

1. Lauwers, B.; Klocke, F.; Klink, A.; Tekkaya, A.E.; Neugebauer, R.; McIntosh, D. 2014. Hybrid processes in manufacturing, CIRP Annals - Manufacturing Technology 63(2): 561-583. http://dx.doi:10.1016/j.cirp.2014.05.003.

2. Duflou, J.R.; Callebaut, B.; Verbert, J.; De Baerdemaeker, H. 2007. Laser assisted incremental forming: Formability and accuracy improvement, CIRP Annals Manufacturing Technology 56(1): 273-276. http://dx.doi:10.1016/j.cirp.2007.05.063.

3. Brehl, D.E.; Dow, T.A. 2008. Review of vibrationassisted machining, Precision Engineering 32(3): 153172 http://dx.doi:10.1016/j.precisioneng.2007.08.003.

4. Patel, N.; Gohil, P. 2012. A review on biomaterials: scope, applications \& human anatomy significance, International Journal of Emerging Technology and Advanced Engineering 2(4): 91-101.

5. Liang, Y.; Dutta, S. P. 2001. Application trend in advanced ceramic technologies, Technovation 21(1): 61-65. 
http://dx.doi:10.1016/S0166-4972(00)00019-5.

6. Axinte, E. 2011. Glasses as engineering materials: A review, Materials and Design 32(4): 1717-1732. http://dx.doi:10.1016/j.matdes.2010.11.057.

7. Shimada, S.; Ikawa, N.; Inamura, T.; Takezawa, N.; Ohmori, H.; Sata, T. 1995. Brittle-ductile transition phenomena in microindentation and micromachining, CIRP Annals - Manufacturing Technology 44(1): 523526. http://dx.doi:10.1016/S0007-8506(07)62377-4.

8. Busch, K.; Hochmuth, C.; Pause, B.; Stoll, A.; Wertheim, R. 2016. Investigation of cooling and lubrication strategies for machining high-temperature alloys, Procedia CIRP 41: 835-840. http://dx.doi:10.1016/j.procir.2015.10.005.

9. Nath, C.; Rahman, M. 2008. Effect of machining parameters in ultrasonic vibration cutting, International Journal of Machine Tools and Manufacture 48(9): $965-$ 974. http://dx.doi:10.1016/j.ijmachtools.2008.01.013.

10. Kumar, M.N.; Kanmani Subbu, S.; Vamsi Krishna, P.; Venugopal, A. 2014. Vibration assisted conventional and advanced machining: A review, In Procedia Engineering 97: 1577-1586.

http://dx.doi:10.1016/j.proeng.2014.12.441.

11. Zhang, C.; Guo, P.; Ehmann, K.F.; Li, Y. 2016. Effects of ultrasonic vibrations in micro-groove turning, Ultrasonics 67: 30-40.

http://dx.doi:http://dx.doi.org/10.1016/j.ultras.2015.12. 016.

12. Grazevicute, J.; Skiedraite, I.; Ostasevicius, V.; Jurenas, V.; Bubulis, A. 2006. Ultrasound application in turn-ing process, Proc. Int. Conf. Vibroengineering, 152-154.

13. Ostasevicius, V.; Gaidys, R.; Dauksevicius, R.; Mikuckyte, S. 2013. Study of vibration milling for improving surface finish of difficult-to-cut materials, Strojniski Vestnik/Journal of Mechanical Engineering 59(6): 351-357.

http://dx.doi:10.5545/sv-jme.2012.856.

14. Pujana, J.; Rivero, A.; Celaya, A.; López de Lacalle, L.N. 2009. Analysis of ultrasonic-assisted drilling of Ti6A14V, International Journal of Machine Tools and Manufacture 49(6): 500-508. http://dx.doi:10.1016/j.ijmachtools.2008.12.014.

15. Toews, H.; Compton, W.; Chandrasekar, S. 1998. A study of the influence of superimposed low-frequency modulation on the drilling process, Precision Engineering 22(1): 1-9.

http://dx.doi:10.1016/S0141-6359(97)00085-8.

16. Sadek, A.; Attia, M.H.; Meshreki, M.; Shi, B. 2013. Characterization and optimization of vibration-assisted drilling of fibre reinforced epoxy laminates, CIRP Annals - Manufacturing Technology 62(1): 91-94. http://dx.doi:10.1016/j.cirp.2013.03.097.

17. Pecat, O.; Brinksmeier, E. 2014. Tool wear analyses in low frequency vibration assisted drilling of CFRP/Ti6Al4V stack material, Procedia $\{$ CIRP $\}$
14: $142-147$.

http://dx.doi:http://dx.doi.org/10.1016/j.procir.2014.03. 050 .

18. Feng, J.; Kim, B.S.; Shih, A.; Ni, J. 2009. Tool wear monitoring for micro-end grinding of ceramic materials, Journal of Materials Processing Technology 209(11): 5110-5116. http://dx.doi:10.1016/j.jmatprotec.2009.02.009.

19. Augustin, G.; Zigman, T.; Davila, S.; Udilljak, T.; Staroveski, T.; Brezak, D.; Babic, S. 2012. Cortical bone drilling and thermal osteonecrosis, Clinical Biomechanics 27(4): 313-325. http://dx.doi:10.1016/j.clinbiomech.2011.10.010.

20. Chacon, G.E.; Bower, D.L.; Larsen, P.E.; McGlumphy, E.A.; Beck, F.M. 2006. Heat production by 3 implant drill systems after repeated drilling and sterilization, Journal of Oral and Maxillofacial Surgery 64(2): 265-269. http://dx.doi:10.1016/j.joms.2005.10.011.

21. Karaca, F.; Aksakal, B.; Kom, M. 2011. Influence of orthopaedic drilling parameters on temperature and histopathology of bovine tibia: An in vitro study, Medical Engineering and Physics 33(10): 1221-1227. http://dx.doi:10.1016/j.medengphy.2011.05.013.

22. Louredo, M.; Díaz, I.; Gil, J.J. 2012. DRIBON: A mechatronic bone drilling tool, Mechatronics 22(8): 1060-1066.

http://dx.doi:10.1016/j.mechatronics.2012.09.001.

V. Ostaševičius, G. Balevičius, R. Zakrasas, J. Baskutienė, V. Jurènas

\section{INVESTIGATION OF VIBRATION ASSISTED DRILLING PROSPECTS FOR IMPROVING MA-CHINING CHARACTERISTICS OF HARD TO MACHINE MATERIALS AT HIGH AND LOW FREQUENCY RANGES}

S u m m a r y

The article investigates applicability of vibration assistance based methods for improvement of machining capabilities of hard to machine materials at low and high frequency ranges. The literature overview of hard to machine materials was performed and two distinct cases were distinguished - machining of hard, brittle materials and machining of human bone tissue. Experimental studies of vibration assisted drilling application for the two cases at high and low frequency ranges were conducted. Experimental results showed improvements of selected criteria in both cases of vibration assisted drilling.

Keyword: Bone tissue, PMMA, VAM, VAD, LFVAD, UAD.

Received January 05, 2016 Accepted April 5, 2016 